\title{
THE STRATEGIC DECISION OF COMMERCIAL SPONSORSHIP AMONG INDONESIA ADVERTISERS: A DELPHI STUDY
}

\author{
La Ode Muhammad Restu Prada \\ Rizal Edi Halim \\ Faculty of Economics and Business, Universitas Indonesia, Jakarta \\ L.M.R.Pradana@gmail.com \\ Rizaledy@gmail.com
}

\begin{abstract}
The study attempts to discern how Indonesia advertiser look at the strategic decision of commercial sponsorship within today Indonesia market, which was done by using Delphi method. The relative importance of commercial sponsorship is examined within the context of overall today marketing and overall advertising approach, budget allocation, and the experts confident regarding the future growth of Indonesia commercial sponsorship. The discussion goes more specific to understand what marketing objective that will be better achieved through commercial sponsorship approach. The result shows that within the context of marketing objective, commercial sponsorship still regarded as a high important approach. However, due to its cost inefficiency nature, Indonesia advertisers reach to the consensus that commercial sponsorship approach should be focused on to deliver marketing objective that aim to deliver product experience to the consumers.
\end{abstract}

Keywords: Delphi method, Sponsor, Commercial Sponsorship, Sponsorship Property, Advertiser, Marketing Objective

\section{INTRODUCTION}

A sponsorship property attracts the brand to sponsor by means of providing the platform that enable brand to touch the consumer, give the feel of the product, even to experience the product itself (Gupta, 2003; Karrh, 2005; Weeks et all, 2008; ARF, 2008; Marieke et all, 2013; Meenaghan, 2013a) - all within the emotional moment, the excitement, and the euphoria during period. Through such excitement, a connection between sponsoring brand and the sponsorship property is developed, in which the effectiveness of such connection can be enhanced by emotive storytelling and by the engagement with the brand (Sher, 2016). While advertising is mostly about delivering persuasive message in controlled manner
(Hastings, 1984), commercial sponsorship approach allows advertisers to spend times with their target consumers throughout the period of event, in which the active flow experiences during a brand encounter will positively affected participants' emotional experiences (Drenger et all, 2008).

Among the many definition of commercial sponsorship, Meenaghan's (1983) is probably cited most often. As a specialist in commercial sponsorship, he argues that commercial

sponsorship is "the provision of assistance either financial or in-kind to an activity by a commercial organization for the purpose of achieving commercial objectives". Such definition does not change much afterward that the International Events Group (IEG, 
2018b) also defines sponsorship as "the relationship between a sponsor and a property, in which the sponsor pays a cash or in-kind fee in return for access to the exploitable commercial potential associated with the property". By such definition, sponsorship distance itself from the likes of charitable donations (Shenfield,1969; Conference Board, 1973) which lack of commercial motives, endorsement (Meenaghan, 1983) which focus on the expectation to product usage, or patronage (Freemont-Smith, 1972) which motives are closer into philanthropic reasons. The definitions also should not be confused with event marketing, because sponsorships are not limited only to event property (IEG, 2018b). For the purposes of our research, and as suggested by IEG sponsorship glossary, we then conceptualize sponsorship broadly to include the following: events, TV Programs, people/organizers personal, and any intellectual property.

The first recorded appearance of commercial sponsorship in modern advertising happened in 1896 modern Olympic Games at Athens, in which Coca-Cola along with Kodak were doing advertisement in the official program (IOC, 2004). The emergence of television had since fostered the demand for commercial sponsorship in the form of TV Program sponsorship (Kissoudi, 2005). The research on brand awareness and image transfer has gained a wide support by 1990s, to the point that Walliser (2003) argued that another objectives other than those two is urgently needed to be addressed. This is the time when sponsorship has evolved from a small-scale activity in a limited number of industrialized countries to a major global industry (Meenaghan, 1998). In the following period between 2001-2011, the literature study by George and Margaret (2014) reveals that within said period the number of research on commercial sponsorship has tripled (573 articles) from the number published between 1980-2000 (196 articles). Also, through a series of regression models and content analysis to a number of scholarly journals, George and Margaret (2014) find that the research on commercial sponsorship has been going more specific into the area of congruence theory and attitude towards sponsors, which were not far from the discussion about image transfer. In the matter of fact, the trend analysis by George and Margaret (2014) noted that the trends seem unlikely to change much in the near future, as they highlighted that congruence is in fact still the most frequently investigated theoretical concept related to the improved processing of sponsorship stimuli.

When discussing new challenge in sponsorship, Meenaghan (2013b) described sponsorship as an extremely versatile platform. The challenge, as well as the opportunity, brought by sponsorship is vast. Its versatility nature means it has a potential to go beyond just advertising, or even as just a medium within advertising practice. And yet, as Meenaghan (2013b) pointed out, sponsorship remain understudy. Many efforts already been put to uncover its image transfer ability, but very little research is done regarding its versatility in delivering various marketing objectives. The same concern was also highlighted by George and Margaret (2014) emphasizing that little is known about the strategic practices and the effective decision strategies a firm will adopt when selecting new sponsorship. The same issue

about how marketing managers make trade-offs when considering new sponsorship opportunities has been addressed by Cornwell (2008) without much attention from scholarly research.

The issue of today sponsorship is well reflected on International Events Group's 2017 Sponsorship Decision-Makers Survey (IEG, 2018a). Among the most important objectives within the strategic decision of sponsorship are to create awareness and to increase brand loyalty, that goes by $50 \%$ and $46 \%$ respectively. Step back to previous 
year, when big events such as the 2016 Summer Olympics and the UEFA Euro 2016 were very prominence to the public interest, the 2016 Sponsorship DecisionMakers Survey data revealed that creating awareness and increasing brand loyalty are as high as $64 \%$ and $63 \%$ respectively (IEG, 2016). Meanwhile the sponsorship ability to change/reinforce image is $46 \%$, down from previously being $47 \%$ in 2016 . Interestingly, sponsorship is also seen as an important tool for more business-related objectives such as to entertain clients/prospects and to stimulate sales/trial/usage, that goes by $33 \%$ and $30 \%$ respectively. Hence, instead of exploiting its ability to do image transfer, many advertisers views sponsorship serve other purpose depending on their marketing objectives.

As clearly point out by International Group Event's survey to decision makers, there is a certain degree of discrepancy between academic and advertiser in viewing what the sponsorship could offer, especially in term of the objectives. Moreover, there has been no systematic attempt to discern the concern from decision maker in the context of the relative importance of sponsorship, especially from Indonesia advertiser. The knowledge of commercial sponsorship, as Meenaghan (2013b) argues, are rarely shared through education body, as compare to those people working in the industry that learn it as part of their job expertise. This is where we come to the next passage, that is to understand the strategic decision of commercial sponsorship among advertisers, especially among Indonesia advertisers. Eventually, in achieving a consensus of opinion for the strategic decision commercial sponsorship will bring Delphi method into consideration

\section{RESEARCH METHODOLOGY}

Within the area where the research is still underdeveloped or where individual expertise is very valuable resource, then Delphi method could be applied well
(Hejblum et al., 2008).

Delphi method is also applicable when the causal study is hardly to be established due to various circumstance such as the degree of complexity within the subject issue itself (Yang and Zhang, 2012). Within the process, Delphi technique collects opinion or understanding from the experts regarding subject in which the evidence is hard to deduce and where the expert opinion is value highly (Avella, 2016) through a series of questions either by interview or questionnaire (Hsu and Sandford, 2007). Compared to common surveys that try to identify "what is," Delphi technique aim to understand "what could/should be" (Miller, 2006). Ludwig (1994) point out the unique point of Delphi which through multiple iterations is able to discern a consensus of expert opinion within certain area of interest.

The use of experts offers the efficient use of the intuition and judgement of a group of persons who are keen observers and have a considerable background knowledge and has cultivated sensitivity to the subject relevance. The whole process is therefore believed can help the researchers to better understand the strategic decision of commercial sponsorship among Indonesia advertisers, as the main subject of this study. After all, compared to common surveys that try to identify "what is," Delphi technique aim to understand "what could/should be" (Miller, 2006).

There are four elements inherent to the design of Delphi method, which work to encourage debate while in the same time taking into consideration the individuality and influence exerted from each professional background (Dalkey, 1972; Hsu and Sandford, 2007; Habibi et all, 2014; Avella 2016). First is the use of expert that have a considerable background knowledge and has cultivated sensitivity to the subject relevance. Second is the anonymity that allows individual freedom of expression by reducing the potential of group pressure for conformity among the experts. Third is 
what known as "controlled feedback" that achieved through conducting several rounds of iteration to achieve the consensus among expert. Each expert participant is allowed to review their previous judgements and reassess the information they provided. It is very expected for the participants to either agree or disagree with general consensus, but the focus should be in how they rationale the different. Along the process, the outcome is expected to come into higher agreement among the participants. Last is the use of statistical analysis to ensure that experts discussion can be well facilitated with a more objective moderation, and thus the outcome of the study will represent the group collective opinions, hence the consensus itself. someone with the authority to fulfil one of the following criteria: 1)

to make direction, 2) to develop, 3) or to place order for sponsorship buying. Such authority is not limited within the company whose brand or product is doing sponsorship but also extended to the media agency who able to exert influence towards the sponsorship decision making and to place order for sponsorship buying. The experts should also have at least 5 years of work experience within strategical role and involved in sponsorship project for at least more than once. This last criterion is important as to avoid unintentional sponsorship involvement as a caretaker in the absence of the true authority. The later

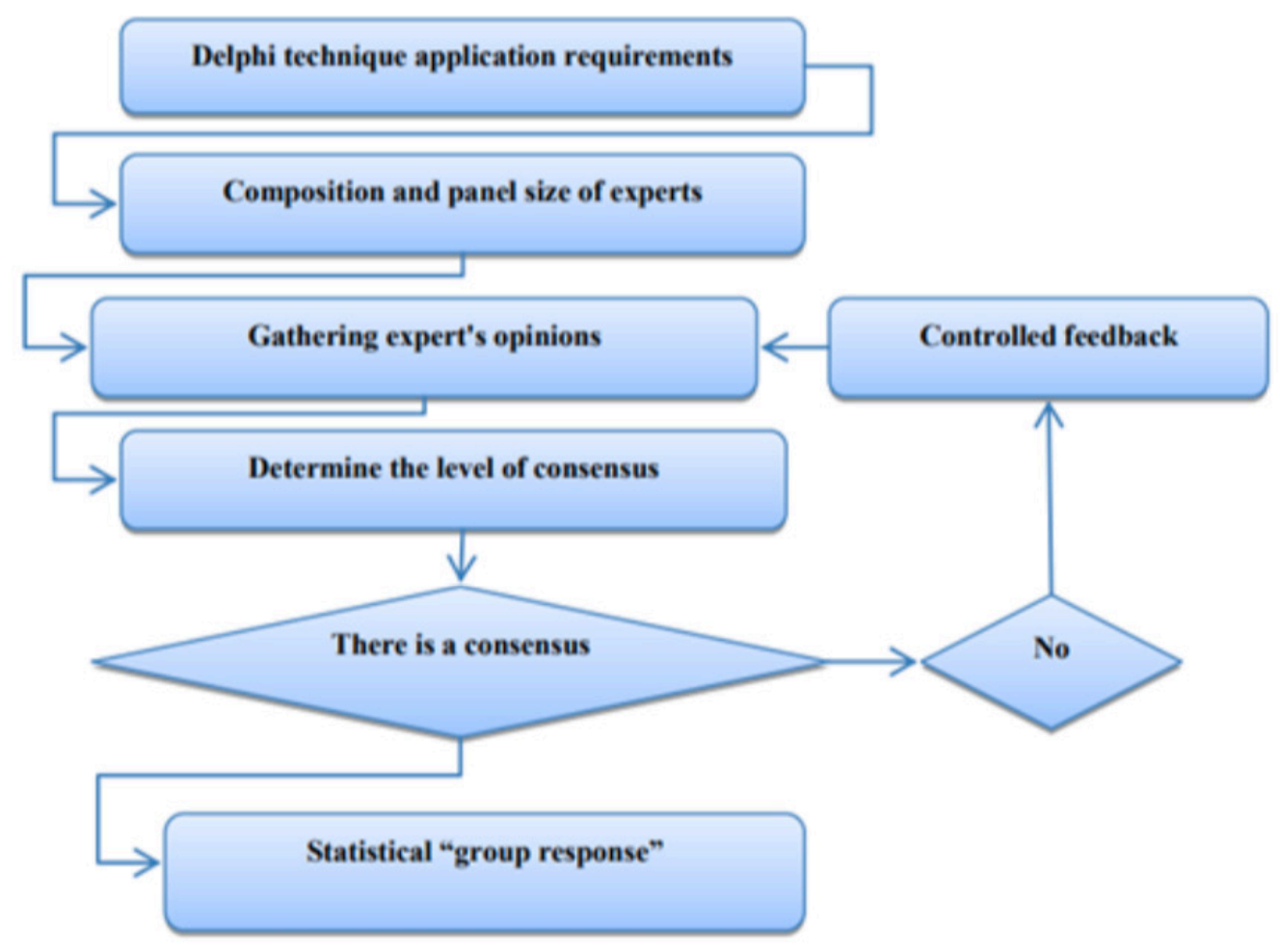

Figure 1. Theoretical Framework of Delphi Technique in Qualitative Research (Habibi et all, 2014)

In forming the expert panel, Hsu and Sandford (2007) noted that there is actually no rigid rules of how Delphi method selecting the panelist. As noted, to be qualified as an expert, one has to meet certain criteria. Within this study, the expert is defined as criterion is to ensure $100 \%$ involvement in the making of sponsorship strategic decision.

The questionnaire was distributed to a total of 19 experts, with $73 \%$ response rate. It is to be noted that when determining the size of the overall panel, the number of 
experts should consider the topics under discussed and the expert availability who can speak knowledgeably about the subject matter, which infer that there is actually no clear standard regarding the panel size (Cuhls, 2004). Accordingly, the participants within this study consist of experts with background varying from market research company, media agency, FMCG company, pharmaceutical company, tobacco company, and automotive company. One participant coming from the research company is at director level and he was once from media agency background with solid experience in media planning. Meanwhile, all the participants coming from media agency are at the minimum of handling client at the level of company, not limited to the brands, thus having a comprehensive view towards the business of the client that they maintain. Lastly, the respondent coming from FMCG company, pharmaceutical company, tobacco company, and automotive company, are all within senior brand manager level, with a vast experience of developing the brand equity. $50 \%$ of said experts belong to midlevel management and another 50\% from upper managements, all of which has more than 5+ involvement in sponsorship projects. Among these experts, $73 \%$ has been involved in sponsorship for 6-10 years, $9 \%$ has been involved for $10-15$ years, $18 \%$ has been involved for $15+$ years. All the experts are those with the authority fulfilling the criteria to make direction, to develop, or to place order for sponsorship buying. All respondents are therefore qualified to participate in the study.

In the round-1, an initial opinion from experts were gathered. The questionnaire was arranged into three main sections. The first section aims to understand the relative importance of commercial sponsorship, gathering various point of views from experts. Participants were asked to rate each question items, related to the relative importance with marketing objectives. 7-point
Likert scale was used, ranging from 0 (no importance $=$ not essential) to 7 (importance $=$ very essential). In addition, experts are invited to provide a justification to supports their rating scores. Then coming to the second section is to understand what marketing objective that can be better achieved through sponsorship approach. This is where experts need to rate specific marketing objectives. It also uses the same 7- point Likert scale with a further clarification for experts to express their opinions. Last section is when experts were asked to rank the marketing objective in the order of decreasing importance (1 - most essential, 9 - least essential). The ranking questions is to determine what are the most essential marketing objective that is believed will be better achieved through sponsorship campaign.

The answers from each expert would then analyzed statistically to measure the central tendencies (section-1 and section-2), and the level of consensus between all participants (section-3). For reasons of confidentiality, the interviewees shall remain anonymous, and thus each expert was allocated a random identification number for reporting and collation of the results. In the first and second sections, the major statistics used are the measure of central tendency by using mean data and inter-quartile range in order to present information concerning the collective judgments of respondents (Hasson, Keeney \& McKenna, 2000; Lin and Song, 2015). Likert scores for each item, per participant, were allocated into categories of importance (low: 0 to 4; moderate: 5; high: 6 and very high: 7). For the rank order in the section-3, Kendall's coefficient of concordance (Kendall's W) was utilized to determine the agreement a consensus criterion representing the level of consensus between the participants. Kendall's coefficient of concordance ranges from 0 to 1 , indicating the degree of consensus reached by the panel (strong consensus for $W>0.7$; moderate consensus for $W=$ 
0.5 ; and weak consensus for $W<0.3$ ). The analysis findings would then determine the form and content for the questionnaire in the next round- 2 .

In the round-2, we compare the rankings from each expert to the group consensus using the statics gathered from round-1. Each expert will be then asked to review their previous answer, giving careful consideration to the opinions of other expert in the group. The top- 2 arguments were being presented as well to help the expert to better understand both the information and judgments made by the consensus. Where the individual rankings substantially differ from the group consensus, further clarifications will be asked and the said experts are also allowed to revise their point of views regarding the sponsorship relative importance. It was examined within the context of overall today marketing and overall advertising approach, within the case for the year with big properties (World Cup, Asian Games), how much budget that should be allocated, and the experts confident regarding sponsorship future by asking them to forecast the growth within the next 5 years. Also, besides the central tendency, it is important to look for any Likert value of $\geq 5$ which will be categorized as importance. Lastly, we will also take a consideration on expert's justification to supports their rating scores.

Starting with the context of today marketing, many experts highlighted about how versatile sponsorship can become in

\begin{tabular}{|c|c|c|c|c|c|c|c|c|c|}
\hline \multirow{2}{*}{ Doint of Discussion } & \multirow{2}{*}{ Mean } & \multicolumn{3}{|c|}{ Interquartile-Range } & \multicolumn{4}{|c|}{ Frequency (\%) per category importance } & \multirow{2}{*}{25} \\
\hline & & Q1 & Q2 & Q3 & Very High & High & Mod & Low & \\
\hline Sponsorship importance in overall today marketing & 5.4 & 5.0 & 6.0 & 6.0 & 7 & 50 & 29 & 14 & 86 \\
\hline Sponsorship importance in comparison to overall advertising approach & 5.0 & 4.3 & 5.0 & 6.0 & 14 & 29 & 29 & 29 & 71 \\
\hline Sponsorship importance for the year with big properties & 5.2 & 4.0 & 5.5 & 6.8 & 29 & 21 & 14 & 36 & 64 \\
\hline Growth within the next 5 years & 5.1 & 4.0 & 5.5 & 6.0 & 14 & 43 & 14 & 29 & 71 \\
\hline Budget allocation $(\%)$ & 11.9 & 7,8 & 12.5 & 20.0 & 29 & 21 & 14 & 36 & 64 \\
\hline
\end{tabular}

Figure 2. Advertisers Consensus Regarding the Sponsorship Relative Importance

previous answer. As for the section-3, a consensus is determined for any question item to achieved $60 \%$.

In the round-3, the experts were given a final opportunity to review their previous answer. Particular questions will be marked should the expert's answers substantially differ from the group, thus require them to provide an explanation why. In short, this is a round "to specify the reasons for remaining outside the consensus" (Pfeiffer, 1968). However, compared to the previous round, only a slight increase in the degree of consensus can be expected (Weaver, 1971; Dalkey and Rourke, 1972; Jacobs, 1996)

\section{RESULT AND DISCUSSION}

\section{Section-1: The Relative Importance of Commercial Sponsorship}

In this section-1, we examine advertisers supporting various marketing objective, ranging from a tool to create brand awareness, trial, and make the brand closer to consumer. However, although experts have an overall positive attitude, there is a big note that sponsorship can only be impactful when there is adequate support. This cause the approach to be very expensive.

When compare to overall advertising approach, the expensive nature of sponsorship is once again being brought up, highlighting the hardly efficient costper-contact. Although sponsorship bringing quite versatility, the experts believe that sponsorship should be treated as complementary because with the same amount of money there are a lot of other medium to reach consumer more efficiently. Among who give low score ( $\leq 4$ scale), there is argument that sponsorships can only 
beneficial only when strong differentiation with other sponsors can be achieved, which often time required sponsors to buy a package that at least cost close to a title sponsor.

For the year with big properties (World Cup, Asian Games), the experts are generally believing that big properties provide a rare opportunity to reach massive audience, as well as to build credibility. However, they also emphasize that unless the brand is capable to create integrated plan, it is better to skip. The impact is very questionable without adequate supports, highlighting the complementary nature of sponsorship.

One question items related to growth forecast help to determined expert's confidents on the feature establishment for sponsorship. Among the expert who shows the confidents, they highlight the area of 1) ever increasing ads clutter; 2) limited ads slot; 3) The increase consumer need for "experience". Meanwhile, some experts point out the fact that brands are becoming more selective in spending the media budget and will require greater measurement to justify the high cost-per-contact as well as the issue with measurement. sponsorship depends very much on the marketing objectives, also highlighting the issue of cost-per-contact, measurement and $\mathrm{ROI}$, and the limited number of sponsorship suitable with brand positioning.

\section{Section-2: Marketing Objective that can be better achieved through sponsorship}

In this section-2, the questionnaire goes more specific to understand what marketing objective that expert panel believe will be better achieved through sponsorship. Similar with section-1, we look at both the central tendency and for any Likert value of $\geq 5$ which will be categorized as importance. In the final or third round, items

were assigned categories of importance based on the greatest participant agreement. Items with the greatest participant agreement in the low importance category (Likert scores 0 to 4 ) were deemed unlikely to be included in marketing objective that should be done through sponsorship; items with the greatest participant agreement in the moderate importance category (Likert scores $=5$ ) were characterized as could be considered for inclusion in the marketing objectives done through sponsorship; and items with the

\begin{tabular}{|c|c|c|c|c|c|c|c|c|c|}
\hline \multirow{2}{*}{ Marketing Objectives } & \multirow{2}{*}{ Mean } & \multirow{2}{*}{$\geq 5$} & \multicolumn{3}{|c|}{ Interquartile-Range } & \multicolumn{4}{|c|}{ Frequency (\%) per category importance } \\
\hline & & & Q1 & Q2 & Q3 & Very High & High & Mod & Low \\
\hline Product Trial/Sampling & 5.6 & 93 & 5.0 & 6.0 & 6.0 & 14 & 50 & 29 & 7 \\
\hline Consumer Activation/Engagement & 5.6 & 86 & 5.0 & 6.0 & 7.0 & 36 & 21 & 29 & 14 \\
\hline Access to Intellectual Property & 5.6 & 85 & 6.0 & 6.0 & 7.0 & 38 & 38 & 8 & 15 \\
\hline Image Transfer & 5.5 & 79 & 5.0 & 6.0 & 6.0 & 21 & 43 & 14 & 21 \\
\hline Sales Traffic & 4.9 & 64 & 3.3 & 6.0 & 6.0 & 14 & 43 & 7 & 36 \\
\hline Awareness & 4.6 & 57 & 3.0 & 5.5 & 6.8 & 29 & 21 & 7 & 43 \\
\hline Niche Marketing Capability & 4.5 & 54 & 2.0 & 5.0 & 7.0 & 31 & 0 & 23 & 46 \\
\hline Clientele \& Stakeholder & 4.1 & 50 & 2.0 & 4.5 & 6.0 & 14 & 21 & 14 & 50 \\
\hline OTHERS & 5.0 & 100 & 5.0 & 5.0 & 5.0 & 0 & 0 & 100 & 0 \\
\hline
\end{tabular}

Figure 3. Marketing Objective Rated by Experts

Another way to see the relative importance of sponsorship is by looking at the budget allocation for sponsorship. The expert's opinion is divided sharply, and some experts decided to leave in the blank the question item arguing that there is no exact percentage or general rule. Regardless of the percentage, the experts suggest that greatest participant agreement in the high to very high importance category (Likert scores $=6$ to 7 ), were characterized as likely to be included as an important marketing objective that can be done through sponsorship. Lastly, we will also take a consideration on expert's justification to supports their rating scores. 
The majority of experts, if not all, already aware the power of sponsorship to help brand positioning by selecting sponsorship property with similar brand image. However, many experts note that since many sponsorship properties doesn't have enough scale, marketer should not rely solely on sponsorship approach. Traditional media such as TV loose spot still becomes the most cost effective in building the brand equity, but sponsorship approach have its place when combining the approach with consumer engagement approach. There are also a number of experts that pointed out the fact that although sponsorship property has its own loyalist, many of those sponsorship properties are lacking the scale, which is undesirable for a typical mass brand or FMCG brand. One common thing when talking about the image transfer is that the majority of experts lamenting that finding a sponsorship with a good balance of strong affinity and a scale is extremely difficult.

In general, although remain important in generating awareness, the majority of experts share common believe that sponsorship cannot be used as a sole tool to generate awareness due

to the concern on cost. The argument already taking consideration the fact that loyal consumers base from sponsorship can be translated into better ad recall and recognition. One expert point out that there is only few occasion when sponsorship can become a main awareness driver, that is when the consumer base is much higher than the brand consumer base. This usually come inherently from highly publicized sponsorship such as Asian Games or World Cup. However, without strong integrated promotion plan, TV loose spots still become the most cost effective.

For the majority of experts, consumer engagement is the single most important objective due to the unique nature of sponsorship approach that cannot be replicate with other medium. In fact, the expert who give lowest rating also bring about the possibility of sponsorship to be incorporated with CRM activity. The experts share common opinion of how sponsorship can help to strengthen the connection between brand and consumers through the two-way engagement, unlike other medium. Sponsorship enable the consumers to explore the brand further, and vice versa it helps brand to understand more of their consumer's needs. As a matter of fact, one expert noted that it is a common practice to find a sponsorship benefit packaged with on ground activities, implying how important sponsorship is for consumer activation.

In general, experts are sharply divided between those who supports sales traffic as marketing objective for sponsorship approach and those who against it. One thing that all experts agree on is the fact that only specific products can ripped the sales benefits. For those who supported sales traffic as marketing objective for sponsorships, they point out how powerful exclusivity rights can help the brand to monopolize the selling throughout the sponsorship period. The experts also believe that sponsorship can help create a situation where consumers can understand in what occasion they will need to consume the product. Lastly, there is also an argument that consumers are less reluctant to consume the product within the period of sponsorship since people perceived the product to be on the same ground with the sponsorship, thus perceived to have similar affinity with the sponsorship property. For the experts who against it, they highlight the fact that the sales from sponsorship is too insignificant to be relied on. This is aside from the fact that not all products can sell well during sponsorship period. They argue that selling is always comes as default benefit offered by the sponsorship committee, but doesn't necessarily will drive noticeable impact. The emphasize should be on giving a positive product experience to consumers instead.

As a complete opposite with sales traffic, almost all experts believe that product 
experience through trial or sampling is crucial, especially for new product. In fact, many experts highlight the importance to identify the consumer base of particular sponsorship property and then let their consumer base experience the product, which the brand eventually hope for said consumer to advocate the products. This also in the hope that the brand will grow in similar affinity with the sponsorship property. Expert also highlight how prominent their product can be with the help of exclusivity rights, thus helping them to be dominant and easy to remember. Deeper consumer understanding is also expected through the process. However, one expert from tobacco industry highlight that moderately he didn't see

any correlation between trial and sponsorship. Unfortunately, experts whose rate the importance $\leq 4$ scale doesn't provide his opinion.

Although some experts pointed out the sponsorship capability to reach a particular target audience, this is a rare kind of marketing objective, which commonly targeted upper-class consumers. Also, this require a high degree of affinity between brand and sponsorship property, in which such sponsorship is rarely available. One expert point out that to do niche marketing, building consumers database is more feasible and can be done in regular basis

The majority of experts are generally agreed on the relative importance of access to intellectual property, especially since it can help to maximize the return of investment. Especially for merchandise format, one expert explain that it can be a very strong tool in helping the product distribution. Through the access to intellectual property, brand can also leverage their affinity, creating a more integrated campaign with the ongoing sponsorship campaign, which one of the way is to create content that are relevant with the sponsorship theme. The approach also offers strong differentiation against another product that didn't buy the sponsorship.
Most experts generally believe that clientele and stakeholder are not the right marketing objective that can be done through sponsorship approach. Some experts even suggested that there are many more efficient ways to build the clientele or to engage the stakeholder. One expert even clearly stated his opinion that such relationship or networking is insignificant and should not be done through sponsorship. One expert who give high rating in this kind of marketing objective state that sponsorship has a potential to be integrated into corporate activities as a performance reward to the stakeholders. There is also mentioned to the needs for CSR. In short, most experts believe that sponsorship can help clientele and to engage stakeholder, however it must not be the main agenda.

Aside from previous marketing objectives, there is one expert who single out other benefit of sponsorship, that is to better understand the consumers, and to gain learning as well as knowledges regarding both the sponsorship activities and the consumers itself.

As a summary, we can formulate the ranking of marketing sponsorship accordingly based on the mean data and $\%$ of respondents who gave a scale of $\geq$ 5 , as in below table. The table provide the understanding that the sponsorship ability to deliver product experience and to engage with consumers is value highly among Indonesia Advertiser.

\section{Section-3: Sponsorship Rank of Importance}

Lastly, in the questionnaire section, experts are asked to rank the marketing objectives based on the most ideal marketing objective to be achieved through sponsorship in the order of decreasing importance (1 - most essential, 9 - least essential). The result will provide the insights in term of what marketing objective that, among Indonesia advertisers, are more likely being done through sponsorship. The difference with the 


\begin{tabular}{|l|ccc|}
\hline & \multicolumn{3}{c|}{ Mean } \\
\hline \multicolumn{1}{|c|}{ Wound-1 } & Round-2 & Round-3 \\
\hline Consumer Activation/Engagement & 0.56 & 0.59 & 0.60 \\
Image Transfer & 2.7 & 2.7 & 2.7 \\
Awareness & 2.4 & 3.2 & 3.2 \\
Product Trial/Sampling & 3.3 & 3.4 & 3.4 \\
Sales Traffic & 3.7 & 4.0 & 4.0 \\
Access to Intellectual Property & 4.8 & 5.3 & 5.3 \\
Niche Marketing Capability & 5.7 & 5.7 & 5.7 \\
Clientele \& Stakeholder & 5.8 & 5.7 & 5.7 \\
OTHERS & 5.9 & 6.6 & 6.6 \\
\hline
\end{tabular}

Figure 4. The Ranking/Order of Importance based on Expert Consensus

questioned items in section- 2 is that the

rank of importance in section-2 put emphasize on individual marketing objective, without considering another better alternative aside from sponsorship approach. In section-3, the experts are encouraged to rank the marketing objectives should they are going to have a sponsorship campaign. In other words, section-3 of the questionnaire try to find out what marketing objective that will be prioritized by the advertiser should they have to implement sponsorship campaign. Section-3 of the questionnaire will eventually add the depth in understanding the strategic decision of sponsorship among Indonesia advertisers.

\section{Figure 4. The Ranking/Order of} Importance based on Expert Consensus

Consumer activation and engagement still becomes the number as the most essential marketing objective to be implemented through sponsorship with a group mean of 2.7. Image transfer comes second with 3.2 group mean, down from first position in earlier round. Interestingly, awareness, although rated relatively low in section-2, were rated as third important with group mean of 3.4, close to the image transfer. Product trial and sampling drop significantly to fourth position with group mean of 4.0. Sales traffic, access to intellectual property, and niche marketing capability are rated relatively similar with group mean of 5.3, 5.7, and 5.7 respectively. Clientele \& stakeholder engagement is rated at the bottom with the group mean of 6.6. Expectedly, any other objective is rated in the lowest.

\section{CONCLUSION AND FUTURE RESEARCH}

The study aims to understand the strategic decision of sponsorship among Indonesia advertisers by doing the Delphi Study. It

attempts to discern the concern from decision maker in the context of the relative importance of sponsorship, especially from Indonesia advertiser. Within the process, Delphi technique collected view from expert advertisers in Indonesia. The result shows that among Indonesia advertisers, product experience top the list for the most important marketing objective to be done through sponsorship. Also, due to its versatility, many experts regard the sponsorship as a high important approach that can deliver various marketing objectives. However, there is a big concern over the cost effectiveness of sponsorship among Indonesia advertisers when comparing sponsorship with other mediums.

The research is of course not without limitation. As per Avella (2016) suggested, ideally there should be a follow up to bring together the panel members for a face-to-face session to gain deeper understanding from 
the answer previously provided. However, considering the timeline and access to reach such high-profile professional, it is highly doubtful that a researcher will have the personal resources to do so. Another thing to note as well is that throughout the process the study was done by using e-mail. One of the reason is to preserve the anonymity of the participants and another reason is due to the difficulty in arranging the face-to- face schedule to conduct the research by using an interview instead of by e-mail.
Based on the results of the study, the following research can be focused on how sponsorship can help a better product experience. A cross-media analysis is also encouraged to be conducted to understand the impact of sponsorship in its relevance with other marketing and promotional activities. Finally, the study can help both academic and advertiser to understand how sponsorship can fit into today marketing, that will ultimately lead to development of the sponsorship best practices.

\section{REFFERENCES}

Advertising Research Foundation (ARF). (2008) Experimental Marketing. New York: ARF. Retrieved, at <http://www.thearf.org/assets/ research-arf-initiatives- experientialengagement> on December 2, 2018

Avella, J. R. (2016) Delphi panels: Research Design, Procedures, Advantages, and Challenges. International Journal of Doctoral Studies. Volume 11

Conference Board. (1973) The Biennial Survey of Company Contributions. New York.

Cornwell, T. B. (2008) State of Art and Science in Sponsorship-Linked Marketing. Journal of Advertising,

Volume 37, Number 3

Cuhls, K. (2004) Delphi Method. Fraunhofer Inst. Syst. Innov. Res. Ger., 93-113

Dalkey, N. C. (1972). The Delphi Method: An Experimental Study of Group Opinion. In N. C. Dalkey, D. L. Rourke, R. Lewis, \& D. Snyder (Eds.) Studies in the quality of life: Delphi and decision-making (pp. 13-54). Lexington, MA: Lexington Books.

Dalkey, N. C., and Rourke, D. L. (1972) Experimental Assessment of Delphi Procedures with Group Value Judgments. In N. C. Dalkey, D. L. Rourke, R. Lewis, \& D. Snyder (Eds.). Studies in the quality of life: Delphi and decision-making (pp. 55-83). Lexington, MA: Lexington Books.

Drenger, J., Gaus, H. \& Jahn, S. (2008) Does Flow Influence the Brand Image in EventMarketing. Journal of Advertising Research, Volume 48 Number 1.

Freemont-Smith, M. R. (1972) Philanthropy and the Business Corporation. Russell-Sage Foundation, New York

George S.S. and Margaret A.J. (2014) The Evolution of Scholarly Research on Sponsorship: Expectations About the Future of This Research Domain. Journal of Promotion Management, Volume 20, Number 3

Gupta, S. (2003) Event Marketing: Issues and Challenges. IIMB Management Review. Volume 15 , Number 2

Habibi, A., Sarafrazi, A., Izadyar, S. (2014) Delphi Technique Theoretical Framework in Qualitative Research. The International Journal of Engineering And Science (IJES). Volume 3, Issue 4

Hasson, F., Keeney, S. and McKenna, H. (2000) Research Guidelines for the Delphi Survey Technique. Journal of Advanced Nursing, 32(4): 1008-1015. 
Hastings G. (1984) Sponsorship Works Differently from Advertising. International Journal of Advertising, Volume 3, Number 2

Hsu, Chia-Chien, and Sandford, B. (2007) The Delphi Technique: Making Sense of Consensus. Practical Assessment Research \& Evaluation, 12(10)

International Events Group (IEG). (2016) What Sponsors Want and Where Dollars will go in 2016. 18 February 2018, http://www.sponsorship.com/IEG/files/71/711f2f01-b6fa46d3-9692- 0cc1d563d9b7.pdf

International Events Group (IEG). (2018a) Sponsorship Glossary. 14 February 2018, http:// www.sponsorship.com/Resources/IEG-Lexicon-and-Glossary.aspx. Grohs, R.; Wagner, U.; Vsetecka,S.( 2004) "Assessing the Effectiveness of sport sponsorship-an empirical examination" Schmalenbach Business Review, Vol. 56 Issue 2, p119-138

International Events Group (IEG). (2018b.) Sponsorship Glossary. Retrieved on 14 February 2018, at http://www.sponsorship.com/Resources/IEG-Lexicon-and-Glossary.aspx.

International Olympic Committee (IOC). (2004) Athens 2004 Marketing Report. Lausanne: International Olympic Committee.

Jacobs, J. M. (1996) Essential Assessment Criteria for Physical Education Teacher Education Programs: A Delphi Study. Unpublished doctoral dissertation, West Virginia University, Morgantown.

Karrh, J. (2005) Why Sponsors Sponsor. Ark. Business online media paper Arkansas News ebusiness biz in Arkansas. Retrieved at <https://www.arkansasbusiness.com/ article/49655/why-sponsors-sponsor- karrh-on-marketing> on May 19, 2018

Kissoudi, P. (2005) Closing the circle: Sponsorship and the Greek Olympic Games from ancient times to the present day. International Journal of the History of Sport, Volume 22, Number 4

Lin, V.S. and Song, H. (2015) A review of Delphi Forecasting Research in Tourism. Current Issues in Tourism Volume 18 Number 2

Ludwig, B. G. (1994) Internationalizing Extension: An exploration of the characteristics evident in a state university Extension system that achieves internationalization. Unpublished doctoral dissertation. The Ohio State University. Columbus

Marieke L. F., Thomas J. L., Daan G.M. (2013) Increasing Sponsorship Effectiveness Through Brand Experience. International Journal of Sports Marketing and Sponsorship, Vol. 14 Issue: 2,

Meenaghan, J.A. (1983) Commercial Sponsorship. European Journal of Marketing, Vol. 17 Issue 7 Meenaghan, T. Grimes, E. (1998) Focusing Commercial Sponsorship on the Internal

Corporate Audience. International Journal of Advertising. Volume 17 Number 1

Meenaghan, T. (2013a) Measuring Sonsorship Performance: Challenge and Direction. Universuty College Dubin: Journal of Psychology and Marketing, 385-393

Meenaghan, T., McLoughlin, D., and McCormack, A. (2013b) New Challenges in Sponsorship Evaluation Actors, New Media, and the Context of Praxis. Psychology and Marketing, Volume 30, Number 5

Miller, L. E. (2006) Determining what could/should be: The Delphi technique and its application. Paper presented at the meeting of the 2006 annual meeting of the Mid-Western Educational Research Association. Columbus. Ohio.

Pfeiffer, J. (1968) New Look at Education. New York: Odyssey Press.

Shenfield, B. (1969) Company Giving. PEP Publications. London: PEP Broadsheet No. 511

Sher, M. (2016) 7 Routes To More Effective Sports Sponsorship. WARC Admap Magazine, February 2016. Retrieved at 
<https://www.warc.com/content/article/admap/7_routes_to_more_effective_sports_ sponsorship/1066 65> on 19 May 2018

Walliser, B. (2003) An international review of sponsorship research: Extension and update. International Journal of Advertising, Volume 22, Number 1

Weaver, W. T. (1971) The Delphi Forecasting Method. Phi Delta Kappan, Volume 52 Number 5

Weeks, C.S., Cornwell, T.B. and Drennan, J.C. (2008) Leveraging sponsorships on the internet: activation,

congruence, and articulation. Psychology \& Marketing, Vol. 25 No. 7, pp. 637-654.

Yang, X., Zeng, L., \& Zhang, R. (2012) Cloud Delphi Method. International Journal of Uncertainty. Fuzziness \& Knowledge-Based Systems. Volume 20 Number 1 